\title{
Carbohydrate Depletion and Leaf Blackening in Protea neriljiolia
}

\author{
Robyn McConchie'and N. Suzanne Lang ${ }^{2}$ \\ Department of Horticulture, Julian C. Miller Hall, Louisiana State University, Baton Rouge, \\ LA 70803
}

Ken C. Gross

.U. S. Department of Agriculture, Agriculture Research Service, Horticultural Crops Quality

Laboratory, Beltsville Agricultural Research Center-West, Beltsville, MD 20705

Additional index words. cut flowers, carbon partitioning, photosynthesis, source-sink

\begin{abstract}
Leaf blackening on cut flower Protea nerii[olia $\mathbf{R}$. Br. stems was dramatically reduced under a 12-hour photosynthetic light period $\left(120 \mu \mathrm{mol} \cdot \mathrm{m}^{-2} \cdot \mathrm{s}^{-1}\right)$ at $25 \mathrm{C}$ for 15 days compared with stems kept in the dark. In the light, addition of $0.5 \%$ exogenous sugar to the vase solution resulted in a maximum of $2.5 \%$ leaf blackening, while stems with no exogenous sugar had a maximum of $16.5 \%$. Continuous darkness resulted in $94 \%$ leaf blackening by day 7, irrespective of sugar treatment. Starch and sucrose concentrations were markedly lower in leaves on darkheld stems than in leaves on stems held in the light; thus, carbohydrate depletion could be the primary stress that initiates leaf blackening. In the light, rates of carbon exchange and assimilate export were similar, indicating that the amount of carbon fixed maybe regulated by sink demand. The pattern of carbon partitioning changed in lightheld leaves of the $0 \%$ sugar treatment during rapid floral expansion and senescence. Inflorescence expansion appears to influence partitioning of photoassimilates and storage reserves into transport carbohydrates; under decreased sink demand, the assimilate export rate decreases and photoassimilates are partitioned into starch. The data suggest that sink strength of inflorescences held in darkness may be responsible for the depletion of leaf carbohydrates and. consequently, blackening.
\end{abstract}

Many Proteaceous species have become important "cut-flower crops. A major postharvest problem of this genus, in particular Protea neriifolia and $\boldsymbol{P}$. eximia, is premature blackening of the leaves (Brink and de Swardt, 1986; Ferreira, 1983; Newman et al., 1989; Paull et al., 1980). Leaves of susceptible species begin to turn black within 3 to 7 days after harvest, severely reducing the market value of a flower stem that otherwise has a potential vase life of 3 to 4 weeks. Leaf blackening appears to be caused by oxidation of the polyphenols and leuco-anthocyanins (Whitehead and de Swardt, 1982) that leak into the cyfosol from the vacuole after rupture of intracellular membranes (Brink and de Swardt, 1986; Ferreira, 1986; Newman et al., 1989). The physiological mechanisms or stresses that initiate rupture of the intracellular membrane and subsequent leaf blackening have not been clearly established.

However, leaf blackening is known to decrease significantly when the influence of the inflorescence sink is eliminated by girdling the stem immediately below the inflorescence or by removing it (Newman et al., 1989; Paull et al., 1980). Blackening is also reduced by lighted postharvest conditions (Newman et al., 1989) and the addition of external sugar to the vase solution at concentrations ranging from $0.5 \%$ to $1.0 \%$ (Brink and de Swardt, 1986; Ferreira, 1986; Newman et al., 1989). These observations suggest that depletion of carbohydrates from leaves, caused by translocation to the strong inflorescence sink, may play a role in initiating the cascade of events that leads to leaf blackening.

Received for publication 25 Mar. 1991. Paper no. 91-28-5169 of the Journal Series, Louisiana Agricultural Experiment Station and Louisiana State Univ. Agriculture Center. We are grateful to V. Lancaster, Kansas State Univ., for statistical assistance and J. Nelson, Goleta, Calif., for donation of flowers. The cost of publishing this paper was defrayed in part by the payment of page charges. Under postal regulations, this paper therefore must be hereby marked advertisement solely to indicate this fact.

lGraduate Research Assistant.

'Assistant Professor.
The in florescence of Protea spp. is classified as an involucrate capitulum, consisting of multiple individual flowers arising from inside the involucral bracts (Johnson and Briggs, 1975). To maximize inflorescence vase life, the Protea inflorescence is generally harvested when the involucral bracts are beginning to unfold. At this stage, many of the flowers inside the bracts are immature and have a high respiratory requirement to complete development (Ferreira, 1986) and produce nectar. Thus, the developing in florescence is probably a very strong sink that cannot be supported adequately by carbohydrate pools in source leaves and stems of cut flowers under dark postharvest conditions.

Despite the evidence that depleted carbohydrate reserves may result in the onset of leaf blackening, carbohydrate metabolism and partitioning have not been examined during a typical postharvest period. Investigation of photosynthetic rates and partitioning of soluble and insoluble nonstructural carbohydrates in response to altered floral sink demand may help clarify some of the physiology of leaf blackening. Here we report on the carbohydrate metabolism of $\boldsymbol{P}$. neriifolia stems used as cut flowers under light and dark conditions to determine whether depleted leaf reserves are related to the onset of leaf blackening. In addition, we investigated the effect of an external carbohydrate source (sucrose) on carbohydrate metabolism and leaf blackening.

\section{Materials and Methods}

Uncut vegetative plant material. To determine the typical nonstructural carbohydrate profile of intact plants, samples were taken from plants of 'Pink Ice' $\boldsymbol{P}$. nenifolia grown in a greenhouse ( $\gg 25 \mathrm{C}$ day/12C night) in 19-liter containers filled with 1 scoria : 1 peat : 1 perlite (by volume). Plants were watered weekly and fertilized with blood meal (12N-OP-OK) and ammonium sulfate (21 N-OP-OK) (Hi-Yield Fertilizers, Volunta

$\overline{\text { Abbreviations: }}$ AER, assimilation export rate; $\mathrm{R}$, carbon exchange rate. 
Purchasing Groups, Bonham, Texas). Based on uniformity, one vegetative stem was selected on each of four plants and divided into 10 phyllotactic divisions (one division equals one complete spiral of leaves) beginning at the distal end. Four leaf punches $(0.5 \mathrm{~cm}$ in diameter) were taken from four randomly selected leaves in each phyllotactic division on the stems and analyzed for soluble and insoluble nonstructural carbohydrates.

Postharvest cut flower stems. Flowering P. neriifolia stems were harvested in Goleta, Calif., during late Sept. 1989 and air-freighted to Baton Rouge, La. Stems were then recut $(1 \mathrm{~cm})$, placed in 1 liter of deionized distilled water containing $50 \mathrm{ppm}$ hypochlorite plus $0.0 \%$ or $0.5 \%$ sucrose (hereafter referred to as $\mathrm{O} \%$ and $0.5 \%$ sugar treatments), and the number of leaves was recorded. Vase solutions were changed every 2 days to coincide with sampling.

Leaf blackening was determined at each sampling by counting the number of leaves with $10 \%$ or more of the leaf area blackened. Inflorescence diameter was measured to determine the progress of inflorescence development. The onset of senescence was determined visually, based on browning of the involucral bracts.

Stems were analyzed under light and dark postharvest conditions for carbon exchange rates (CER), assimilate export rate (AER), and leaf carbohydrate composition. The limited number of leaves within a phyllotactic division, as well as on the whole stem of the commercially harvested stems, precluded us from sampling on a phyllotactic basis over the 15-day postharvest period.

Dark and light experiments. Four stems' randomly selected from each sugar treatment were placed in a growth chamber (Environmental Growth Chambers, Chagrin Falls, Ohio) at 25 \pm IC in either continuous darkness or a photosynthetically active radiation (PAR) of $120 \mu \mathrm{mols} \cdot \mathrm{m}^{-2} \cdot \mathrm{s} 1$ for $12 \mathrm{~h}$ each 24-h interval. To ensure that removal of leaf disk samples did not confound other measurements, a nonwounded control was included for each sugar treatment. This control consisted of a complete replication of stems for which all developmental and photosynthetic characteristics were measured, but no leaf disks were removed.

Carbon exchange. Net carbon exchange $\left(\mathrm{CO}_{2}\right)$ was measured on a randomly selected leaf from each stem using a portable infrared gas analyzer (LI-COR Model Li-6200, Lincoln, Neb.). Sample leaves were placed in a 0.25-liter cuvette, and air with $\approx 350 \mathrm{ppm} \mathrm{CO}_{2}$ was passed over the adaxial and abaxial leaf surfaces at a flow rate of $1100 \mu \mathrm{mol} \cdot \mathrm{s}$ 1. The difference in $\mathrm{CO}_{2}$ concentration between air supplied to and exhausted from the cuvette was" measured (mean of two measurements). Net carbon exchange in the dark experiment was measured as $\mathrm{CO}_{2}$ evolution and expressed as milligrams of $\mathrm{CO}_{2}$ per square decimeter per hour. In the light experiment, CER was measured as photosynthetic uptake of $\mathrm{CO}_{2}$ and expressed as milligrams of $\mathrm{CH}_{2} \mathrm{O}$ per square decimeter per hour using the method of Hesketh and Moss (1963).

Assimilate export rate. Four leaf disks $(0.5 \mathrm{~cm}$ in diameter $)$ were removed from two sample leaves on each stem at the beginning $\left(\mathrm{T}_{1}\right)$ and end $\left(\mathrm{T}_{z}\right)$ of a 5 -h sampling period. CER was measured on one of the sample leaves midway between $T_{1}$ and $\mathrm{T}_{2}$. Leaf disks were frozen at $-80 \mathrm{C}$, Iyophilized, and weighed to calculate the rate of dry weight change per unit leaf area over the sampling period. AER was then estimated using the method of Terry and Mortimer (1972).

Carbohydrate extraction and analysis. Soluble carbohydrates were extracted from Iyophilized leaf disks in a total of $9 \mathrm{ml}$ of
$80 \%$ ethanol (v/v) and evaporated to dryness according to the method of Robbins and Pharr (1988). The samples were redissolved in $2 \mathrm{ml}$ of $80^{\circ} \%$ ethanol, and soluble carbohydrates per unit leaf area were determined using high-performance liquid chromatography (HPLC) as described by Picha (1985). Sugars were identified and quantified based on retention times and areas under the peak for the following sugar standards: $0.4 \%$ xylose, $0.1 \%$ fructose, O. $1 \%$ glucose, $0.2 \%$ sucrose, and $0.1 \%$ maltose.

For further analysis of soluble carbohydrates, the dried samples of HPLC fractions were made into their alditol acetate derivatives as described by Blakeney et al. (1983). Monosaccharide derivatives were then separated on a $25-\mathrm{m} 5 \%$ phenylmethylsilicone column $(0.2 \mathrm{~mm}$ id. $)$ using capillary gas chromatography conditions as described by Gross (1986). Monosaccharide derivatives were detected by gas chromatography/mass spectrophotometry (GC/MS) and the spectra compared with standards.

The pellet from the soluble carbohydrate ethanolic extaction was used for starch analysis. Starch concentrations were determined enzymatically by detecting released glucose (Robbins and Pharr, 1988).

Statistical analysis. Each data set was analyzed as a repeated measures design with a one-way treatment structure $(0.5 \%$ sugar or O\% sugar) (Milliken and Johnson, 1984). Measurements were taken every 2 days for 7 days in the dark experiment (by which time all leaves had blackened) and 15 days for the light experiment. Light and dark experiments could not be compared directly since replicate environmental growth chambers were unavailable.

\section{Results}

There was no wounding response detected on treatment stems compared to the nonwounded controls in either the light or dark experiments (data not shown).

Dark experiment. The onset of leaf blackening under continuous darkness at 25C was rapid (Fig. 1). By day 7, >94\% of the leaves in both treatments had at least $10 \%$ leaf area black-

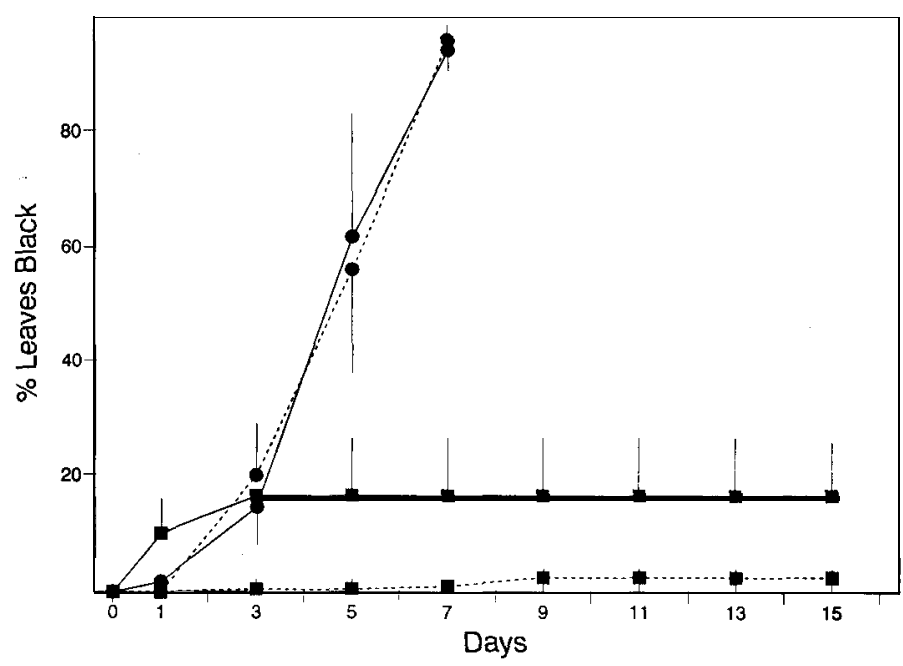

Fig. 1. Percentage of leaves with at least $10 \%$ blackened leaf area in $P$. neriifolia cut flower stems at $25 \mathrm{C}$. Stems in $0 \%$ sugar vase solutions under continuous darkness (.-o), or $12 \mathrm{~h}$ of photosynthetic light $\left(120 \mu \mathrm{mol} \cdot \mathrm{m}^{-2} \cdot \mathrm{s}^{-1}\right)(-)$. Stems in $0.5 \%$ sugar vase solutions under continuous darkness (.----.) or $12^{-} \mathrm{h}$ of photosynthetic light $\left(120 \mu \mathrm{mol} \cdot \mathrm{m}^{-2} \cdot \mathrm{s}^{-1}\right)(\mathbf{- - - -})$. Vertical lines equal $1 \mathrm{SE}$ $(\mathrm{n}=4)$. Bars smaller than symbols are not shown. 
Table 2. CER, AER, and percentage of fixed carbon exported (\% export) for leaves of Protea neriifolia under a 12-h photosynthetic light period $\left(120 \mu \mathrm{mol} \cdot \mathrm{m}^{-2} \cdot \mathrm{s}^{-1}\right)$ with $0 \%$ or $0.5 \%$ sugar in the vase solution.

\begin{tabular}{|c|c|c|c|c|c|c|}
\hline \multirow[b]{3}{*}{ Day } & \multicolumn{3}{|c|}{$0 \%$ Sugar } & \multicolumn{3}{|c|}{$0.5 \%$ Sugar } \\
\hline & CER & AER & \multirow[b]{2}{*}{$\%$ Export } & CER & AER & \multirow[b]{2}{*}{ \% Export } \\
\hline & \multicolumn{2}{|c|}{$\left(\mathrm{mg} \mathrm{CH} \mathrm{CH}_{2} \mathrm{O} / \mathrm{dm}^{2}\right.$ per $\left.\mathrm{h}\right)$} & & \multicolumn{2}{|c|}{$\left(\mathrm{mg} \mathrm{CH} \mathrm{CH}_{2} \mathrm{O} / \mathrm{dm}^{2}\right.$ per $\left.\mathrm{h}\right)$} & \\
\hline 1 & $0.47 \pm 0.05^{y}$ & $0.45 \pm 0.05$ & 96 & $0.55 \pm 0.14$ & $0.54 \pm 0.14$ & 98 \\
\hline 3 & $0.87 \pm 0.45$ & $0.86 \pm 0.45$ & 99 & $0.70 \pm 0$ & $0.69 \pm 0.24$ & 99 \\
\hline 5 & $0.35 \pm 0.04$ & $0.35 \pm 0.05$ & 100 & $0.31 \pm 0.07$ & $0.31 \pm 0.07$ & 100 \\
\hline 7 & $1.73 \pm 0.48$ & $1.72 \pm 0.48$ & 99 & $0.86 \pm 0.19$ & $0.84 \pm 0.19$ & 98 \\
\hline 9 & $1.31 \pm 0.33$ & $1.30 \pm 0.33$ & 99 & $0.95 \pm 0.49$ & $0.95 \pm 0.49$ & 100 \\
\hline 11 & $0.34 \pm 0.14$ & $0.33 \pm 0.14$ & 97 & $0.70 \pm 0.43$ & $0.69 \pm 0.42$ & 99 \\
\hline 13 & $0.18 \pm 0.04$ & $0.16 \pm 0.03$ & 89 & $0.21 \pm 0.05$ & $0.20 \pm 0.05$ & 95 \\
\hline 15 & $0.11 \pm 0.07$ & $0.10 \pm 0.07$ & 91 & $0.30 \pm 0.05$ & $0.30 \pm 0.05$ & 100 \\
\hline
\end{tabular}

xPercent fixed carbon exported $=($ AER/CER $) \times 100$.

${ }^{\text {SSE }}(n=4)$.

be regulated by AER. Highest CER and AER for the O\% sugar treatment occurred on days 7 and 9 . In the $0.5 \%$ sugar treatment, highest CER and AER also occurred on days 7 and 9 but were less $(=5070$ and $27 \%$, respectively) than the $0 \%$ sugar treatment.

Starch concentrations between the sugar treatments differed significantly overall $(P=0.006)$. Addition of $0.5 \%$ sugar resulted in significantly higher starch concentrations from day 5 onward $(P=0.05$ to 0.003 ) (Fig. $2 \mathrm{~F}$ ), reaching $>40070$ of the initial concentration. In the $0 \%$ sugar treatment, starch concentrations declined over the first 7 days to a level similar to that measured in the dark experiment. After day 7, starch concentrations in this treatment increased slightly.

There was no significant difference overall $(P=0.86)$ between the treatments for leaf sucrose concentrations (Fig. 2G), which generally increased.

Concentrations of the unknown monosaccharide fluctuated over the experiment period and were not affected by the sugar treatment (Fig. 2H). Concentrations of this monosaccharide in both treatments were higher than sucrose concentrations throughout the 13 days (Fig. 2G).

Uncut vegetative stems. The position of the phyllotactic division influenced the concentration of the major leaf carbohydrates (Figs. 3 and 4). Starch concentrations increased basipetally, rising sharply below the fifth phyllotactic division (Fig. 3). In contrast, the unknown monosaccharide concentration was highest in the young leaves, decreasing linearly as leaves became older (Fig. 4). Leaf sucrose concentrations remained generally constant regardless of position (Fig. 4).

Starch concentrations below the third phyllotactic division in uncut stems were higher than those measured in leaves of the cut flower stems for both sugar treatments in the dark and light postharvest experiments (Figs. $2 \mathrm{~B}$ and $\mathrm{F}$ and 3). The unknown monosaccharide concentrations in the cut stems in the light were similar to concentrations in the most basipetal phyllotactic divisions on uncut stems (Figs. $2 \mathrm{H}$ and 4). However, concentrations of the unknown monosaccharide in both sugar treatments in darkness were similar to concentrations in the most acropetal phyllotactic divisions of uncut vegetative stems (Figs. 2D and 4). Leaf sucrose concentrations of cut flower stems were higher than those of uncut stems (Figs. $2 \mathrm{C}$ and $\mathrm{G}$ and 4).

\section{Discussion}

Presence of photosynthetic light during postharvest storage dramatically retarded $P$. neriifolia leaf blackening (Fig. 1). Pho-

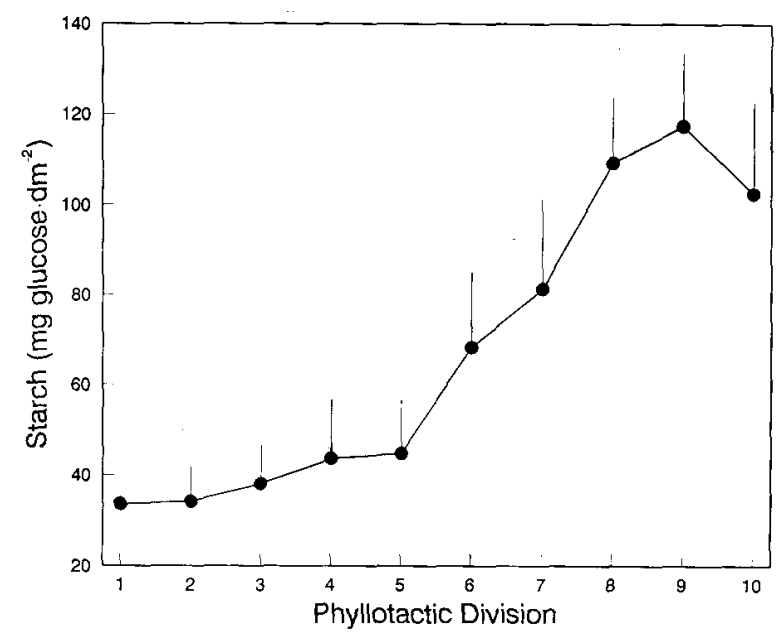

Fig. 3. Leaf starch concentration in 10 phyllotactic divisions from the distal end (division 1) to the basal end (division 10) of uncut greenhouse-grown vegetative stems of Protea neriifolia $C V$. 'Pink Ice'. Vertical lines equal $1 \mathrm{SE}(\mathrm{n}=4)$. Bars smaller than symbols are not shown.

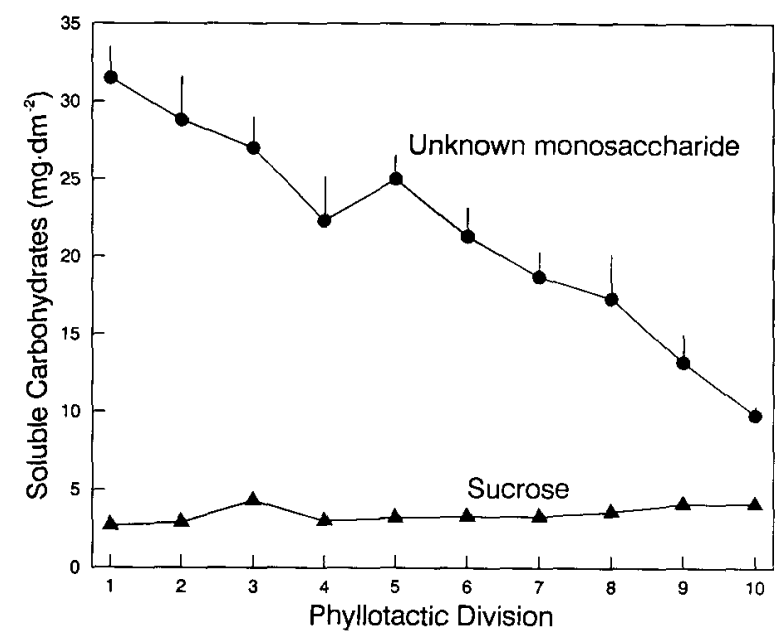

Fig. 4. Leaf unknown monosaccharide (.) and sucrose $\boldsymbol{\Delta}$ concentrations in 10 phyllotactic divisions from the distal end (division 1). to the basal end (division 10) of uncut greenhouse-grown vegetative stems of Protea neriifolia $C V$. 'Pink Ice'. Vertical lines equal $1 \mathrm{SE}$ $(\mathrm{n}=4)$. Bars smaller than symbols are not shown. 
tosynthesis supplies the developing inflorescence with respiratory substrate and carbon skeletons for other metabolizes (Halevy and Mayak, 1979). Lack of respiratory substrate can lead to degradation of cellular components in floral tissue, including membranes, to fulfill carbohydrate demand (Coorts, 1973). In cut flower stems of $P$. neriifolia, carbohydrate reserves in leaves are probably depleted by the strong inflorescence sink, resulting in membrane degradation, polyphenol leakage and oxidation, and leaf blackening (Brink and de Swardt, 1986; Newman et al., 1989). Our results demonstrate that leaves in light actively photosynthesize (Table 2) and contribute to the carbohydrate pool (Fig. $2 \mathrm{~F}$ and $\mathrm{G}$ ), thus leading to reduced leaf blackening.

Addition of exogenous sugar to vase solutions for cut flowers can enhance longevity and quality by improved water status, continued growth, and delayed climacteric respiration in many species (Halevy and Mayak, 1979). Optimum sugar concentration varies with species, duration of treatment, and stage of floral development (Halevy and Mayak, 1981). Concentrations in the range of $0.5 \%$ to $1 \%$ are recommended for P. nen.ifolia to enhance inflorescence quality and reduce the onset of leaf blackening (Brink and de Swardt, 1986; Newman et al., 1989). In our study, a vase solution with $0.5 \%$ sugar did not delay leaf blackening in darkness (Fig. 1). A small, though statistically insignificant reduction, is evident in the light experiment (Fig. 1). Possibly, the onset of blackening may have been induced, but not expressed, during the two days of shipping and was irreversible under dark conditions even with an external sugar source. Alternatively, $0.5 \%$ sugar in the vase solution may not have been sufficient to compensate for carbohydrate demand. Leaves on stems in the light may have been able to meet carbohydrate requirements from fixed carbon and, hence, maintain leaf cell integrity.

Developing flowers compete for carbohydrates and other metabolizes (Halevy, 1987). As P. neriifolia inflorescences are harvested before full maturity, demand for an adequate supply of assimilates to complete development may continue after harvest. Our data are consistent with the hypothesis that the inflorescence sink is responsible for depleting carbohydrate reserves from leaves. In the light experiment without exogenous sugar, starch concentrations declined over the first 7 days (Fig. $2 \mathrm{~F}$ ), which coincides with the period of rapid expansion and development of the inflorescence (Fig. 2E). Photoassimilates may not have been sufficient to meet demand during this period and, thus, storage reserves were mobilized to support floral development. The onset of floral senescence by day 9 was concurrent with a gradual accumulation of starch in leaves, suggesting a diminished inflorescence sink demand. Reduced sink demand has been reported to result in decreased AER and a corresponding increase in starch concentration (Robbins and Pharr, 1988; Rufty and Huber, 1983). Our results imply that when inflorescences expand, photoassimilates and storage reserves are partitioned into transport carbohydrates; under decreased sink demand, AER decreases and photoassimilate can be partitioned into starch (Table 2 and Fig. 2F).

In the light experiment with exogenous sugar, leaf carbohydrate status 'was luxurious, as evidenced by the large increase in starch concentration (Fig. 2F). Leaves possibly were able to partition sugar from the vase solution into storage carbohydrates while maintaining healthy foliage and inflorescence. Exogenous sugar also appeared to prevent senescence of the inflorescence during the postharvest period. Exogenously supplied sugar has been reported to be incorporated into proteins and carbohydrates in roses (Sacalis and Chin, 1976). Also, it has been reported that degradation and leakage of membranes in 'Mercedes' rose petals was slowed when stems were treated with $2 \%$ sugar solution (Goszcynska et al., 1990).

Ferreira (1986) reported that the P. neriifolia inflorescence follows a climacteric pattern of respiration, which precedes the final stages of senescence (Halevy and Mayak, 1979). Our data suggest that inflorescences in the light experiment without exogenous sugar reached a respiratory peak near day 7 and subsequently senesced. The corresponding peak in leaf CER and AER for that treatment may represent the response to a rapidly respiring inflorescence (Table 2).

Leaf blackening in $P$. neriifolia reportedly has been reduced temporarily through the use of antioxidant dips and low $-\mathrm{O}_{\mathrm{z}}$ atmosphere storage (R. Jones, personal communication). It has been suggested that the antioxidant glutathione, which maybe synthesized in the light (Alscher, 1989), could be responsible for the inhibition of the oxidation processes that lead to leaf blackening. While our study clearly implicates carbohydrate depletion as the primary stress leading to leaf blackening, the role of light in promoting antioxidant activity may also be a factor.

\section{Literature Cited}

Alscher, R.G. 1989. Biosynthesis and antioxidant function of glutathione in plants. Physiol. Plant. 77:457464.

Blakeney, A. B., P.J. Harris, R.J. Henry, and B.A. Stone, 1983. A simple and rapid preparation of alditol acetates for monosaccharide analysis. Carbohydrate Res. 113:291-299.

Boeyens, J. C. A., J.L.C. Marais, and G.W. Perold. 1983. The occurrence, conformation and crystal structure of 1,5-anhydro-D-ghrcitol in Protea spp. Photochemistry 22:1959-1960.

Brink, J.A. and G.H. de Swardt. 1986. The effect of sucrose in a vase solution on leaf browning of Protea nen.rfolia. Acts Hort. 185:11 1119.

Coorts, G.D. 1973. Internal metabolic changes in cut flowers. HortScience 8:195-198.

Ferreira, D.I. 1983. Prevention of browning of leaves of Protea neriifolia R. Br. Acts Hort. 138:273-276.

Ferreira, D.L 1986. The influence of temperature on the respiration rate and browning of Protea neriifolia $\mathrm{R}$. Br. inflorescences. Acts Hort. 185:121-129.

Flore, J.A. and A.N. Lakso. 1990. Environmental and physiological regulation of photosynthesis in fruit crops. Hort. Rev. 11:111-157.

Gary, C. 1989. Temperature and time-course of the carbon balance of vegetative tomato plants during prolonged darkness: Examination of a method of estimating maintenance respiration. Ann. Bet. 63:449458.

Goszcynska, D., H. Itzhaki, A. Borochov, and A.H. Halevy. 1990. Effects of sugar on physical and compositional properties of rose petal membranes. Scientia Hort. 43:313-320.

Gross, K.C. 1986. Composition of ethanol insoluble polysaccharides in water extracts of ripening tomatoes. Photochemistry 25:373-376.

Halevy, A.H. 1987. Assimilate allocation and flower development. p. 363-378. In: J.G. Atterton (cd.). Manipulation of flowering. Butterworths, London.

Halevy, A.H. and S. Mayak. 1979. Senescence and postharvest physiology of cut flowers, Part 1. Hort. Rev. 1:204-236.

Halevy, A.H. and S. Mayak. 1981. Senescence and postharvest physiology of cut flowers, Part 2. Hort. Rev. 3:59-143.

Hesketh, J.D. and D.N. Moss. 1963. Variation in response of photosynthesis to light. Crop Sci. 3:107-110.

Johnson, L.A.S. and B.G. Briggs. 1975. On the Proteaceae-The evolution and classification of a southern family. Bet. J. Linn. Sot. 70:83-182.

Milliken, G.A. and D.E. Johnson. 1984. Analysis of messy data. vol. 1. Designed experiments. Van Nostrand Reinhold, New York. p. 323-350. 
Newman, J. P., W. van Doom, and MS. Reid. 1989. Carbohydrate stress causes leaf blackening. J. Intl Protea Assn. 18:44-46.

Paull, R. E., R.A. Criley, P.E. Parvin, and T. Goo. 1980. Leaf blackening in cut Protea eximia; The importance of water relations. Acts Hort. 113:159-166.

Picha, D.H. 1985. HPLC determination of sugars in raw and baked sweet potatoes. J. Food Sci. 50:1189-1190, 1210.

Plouvier, M.V. 1964. Sur la recherche des polalcools et des hétérosides cyanogénétiques chez quelque Protéacées. Comptes Rendus Acad. Sci. Paris 259:665.

Robbins, N.S. and D.M. Pharr. 1988. Effect of restricted root growth on carbohydrate metabolism and whole plant growth of Cucumis sativus L Plant Physiol. 87:409413.
Rufty, T. W. and S.C. Huber. 1983. Changes in starch formation and activities of sucrose phosphate synthase and cytoplasmic fructose1,6-bisphosphate in response to source-sink alterations. Plant Physiol. $72: 474480$.

Sacalis, J.N. and C.K. Chin. 1976. Metabolism of sucrose in cut roses. 1. Comparison of sucrose pulse and continuous sucrose uptake. J. Amer. Soc. Hort. Sci. 101:254-257.

Terry, N. and D.C. Mortimer. 1972. Estimate of the rates of mass carbon transfer by leaves of sugar beet. Can. J. Bet. 50: 10491054 .

Whitehead, C.S. and G.H. de Swardt. 1982. Extraction and activity of polyphenoloxidase and peroxidase from senescing leaves of Protea neriifolia. S. Afr. J. Bet. 1:127-130. 